\title{
Loss of cell adhesion molecule CHL1 improves homeostatic adaptation and survival in hypoxic stress
}

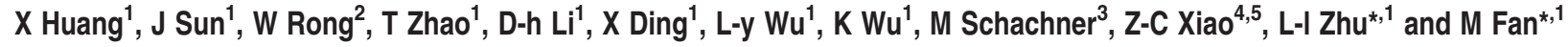

Close homologue of $L 1$ (CHL1) is a transmembrane cell adhesion molecule that is critical for brain development and for the maintenance of neural circuits in adults. Recent studies revealed that $\mathrm{CHL} 1$ has diverse roles and is involved in the regulation of recovery after spinal cord injury. CHL1 expression was downregulated in the cerebral cortex, hypothalamus, and brain stem after the induction of acute hypoxia (AH). In the current study, we sought to address the role of $\mathrm{CHL} 1$ in regulating homeostasis responses to hypoxia using $\mathrm{CHL} 1-$ knockout $\left(\mathrm{CHL}^{-l-}\right)$ mice. We found that, compared with wild-type littermates, $\mathrm{CHL1}^{-I-}$ mice showed a dramatically lower mortality rate and an augmented ventilatory response after they were subjected to $\mathrm{AH}$. Immunofluorescence staining revealed that CHL1 was expressed in the carotid body (CB), the key oxygen sensor in rodents, and $\mathrm{CHL} 1$ expression level in the $\mathrm{CB}$ as assayed by western blot was decreased after hypoxic exposure. The number of glomus cells and the expression of tyrosine hydroxylase (a marker for glomus cells) in the $\mathrm{CB}$ of $\mathrm{CHL} 1^{-1-}$ mice appeared to be increased compared with $\mathrm{CHL} 1^{+I+}$ mice. In addition, in the ex vivo $\mathrm{CB}$ preparation, hypoxia induced a significantly greater afferent nerve discharge in $\mathrm{CHL}^{-1-}$ mice compared with $\mathrm{CHL} 1^{+I+}$ mice. Furthermore, the arterial blood pressure and plasma catecholamine levels of $\mathrm{CHL} 1^{-1-}$ mice were also significantly higher than those of $\mathrm{CHL} 1^{+I+}$ mice. Our findings first demonstrate that $\mathrm{CHL} 1$ is a novel intrinsic factor that is involved in $\mathrm{CB}$ function and in the ventilatory response to $\mathrm{AH}$.

Cell Death and Disease (2013) 4, e768; doi:10.1038/cddis.2013.284; published online 15 August 2013

Subject Category: Neuroscience

Close homologue of $L 1$ (CHL1), a close homolog of $L 1$, is a transmembrane cell adhesion molecule that contains six Ig-like domains and 4-5 fibronectin type III homologous domains in its extracellular region and was first identified in 1996 . $^{1}$ $\mathrm{CHL} 1$ is regionally expressed in the central nervous system, spinal cord, and peripheral nervous system and is critical for neurite outgrowth, neuronal survival, and axonal guidance during development and in the maintenance of neural circuits in adults. ${ }^{2,3}$ In humans, CHL1 (also referred to as CALL) is a candidate gene involved in 3p-syndrome-associated mental impairment. ${ }^{4}$ Recent studies demonstrated that $\mathrm{CHL} 1$ is involved in the development of different human cancers and is downregulated/silenced in a majority of primary tumors and upregulated in association with invasive/metastatic growth. ${ }^{5}$ Moreover, CHL1 has been shown to be a novel physiological substrate of beta-site APP cleaving enzyme 1 (BACE1) in vitro and in vivo and may be involved in the regulation of $A D$ development. ${ }^{6}$

The first CHL1-knockout mice were generated in $2002{ }^{7}$ $\mathrm{CHL} 1$ deficiency resulted in misguided axonal projections and aberrant axonal connectivity within the central nervous system, and the mice displayed impaired cognitive functions and sensorimotor co-ordination as well as aberrant emotional reactivity. ${ }^{8}$ Further studies indicated that $\mathrm{CHL} 1$ also performs important functions in the lesioned nervous system. The expression of CHL1 was elevated in glia cells in injured optic nerves, and CHL1-knockout mice displayed improved recovery from spinal cord injury owing to a reduction in the glial fibrillary acidic protein (GFAP) expression when compared with wild-type mice. ${ }^{9}$ In our previous work, we found that CHL1 was expressed in neural stem cells and negatively regulated their proliferation and differentiation. ${ }^{10}$ In addition, we found that CHL1 protein expression was downregulated in the cerebral cortex, hypothalamus, and brain stem after the induction of acute hypoxia $(A H)$, suggesting that $\mathrm{CHL} 1$ might have an important role in the regulation of neuronal responses to hypoxia. ${ }^{11}$

Oxygen has a central role in cell metabolism and animal physiology. Once oxygen supplies decrease, even temporarily, irreversible cellular damage can result. As part of the mammalian adaptation to hypoxic environments, an important response to hypoxia is to increase breathing and replenish oxygen from the air. The carotid body $(\mathrm{CB})$ is the main arterial chemoreceptor that senses the blood $\mathrm{O}_{2}$ concentration.

\footnotetext{
${ }^{1}$ Department of Cognitive Sciences, Beijing Institute of Basic Medical Sciences, Beijing 100850, China; ${ }^{2}$ Department of Physiology, Shanghai Jiaotong University School of Medicine, Shanghai 200025, China; ${ }^{3}$ Department of Cell Biology and Neuroscience, Rutgers, The State University of New Jersey, 604 Allison Road, Nelson Laboratory D251, Piscataway, NJ 08854, USA; ${ }^{4}$ Department of Anatomy and Developmental Biology, Monash University, Clayton, Victoria 3800, Australia and ${ }^{5}$ Institute of Molecular and Clinical Medicine, Kunming Medical College, Kunming, China

*Corresponding author: L-I Zhu or M Fan, Department of Cognitive Sciences, Beijing Institute of Basic Medical Sciences, No. 27 Taiping Rd, Beijing 100850, China. Tel: + 861068210077 ext 931315; Fax: + 8610 68213039; E-mails: linglingzhu@hotmail.com or fanming@nic.bmi.ac.cn

Keywords: CHL1; acute hypoxia; homeostatic adaptation; survival

Abbreviations: $\mathrm{CHL1}$, close homologue of L1; AH, acute hypoxia; AHH, acute hypobaric hypoxia; $\mathrm{CB}$, carotid body; TH, hydroxylase; GFAP, glial fibrillary acidic protein; BACE1, beta-site APP cleaving enzyme 1; HVR, hypoxic ventilatory response

Received 21.5.13; revised 03.7.13; accepted 04.7.13; Edited by A Stephanou
} 
Upon exposure to $\mathrm{AH}$, neurosecretory type-I glomus cells release transmitters that activate afferent sensory fibers that project to the brain stem to elicit hyperventilation and sympathetic activation. The increased ventilation and sympathoexcitation triggered by hypoxia represent the important homeostasis responses for mammalian adaptation to acute hypoxic environments and survival. ${ }^{12,13}$ Molecules such as hypoxiainducible factor $1 \alpha$, the small membrane-anchoring $D$ subunit of mitochondrial succinate dehydrogenase, heme oxygenase 2 , and NOX4 et al. have been reported to be involved in the regulation of the $\mathrm{CB}$ oxygen-sensing function. ${ }^{14,15}$ However, the precise molecular mechanisms underlying the hypoxic response in the $\mathrm{CB}$ remain poorly understood. Experimental studies on the $\mathrm{CB}$ are challenging because of the small size of the organ, which precludes elaborate biochemical and molecular biology experiments. To our knowledge, there are no reports of the involvement of cell adhesion molecules in this process.

The current study was designed to test the possible involvement of CHL1 in the regulation of the homeostasis responses to $\mathrm{AH}$. We found that CHL1 is expressed in mouse $\mathrm{CB}$ and its deficiency results in hyperplasia of CB. Importantly, $\mathrm{CHL}^{-1-}$ mice showed an augmented ventilatory response and a lower mortality rate when they were subjected to $\mathrm{AH}$. The blood pressure and plasma catecholamine levels of $\mathrm{CHL}^{-/-}$mice were also higher than those of $\mathrm{CHL}_{1}^{+/+}$ mice. The findings suggest that $\mathrm{CHL} 1$ might have a role in the chemoreceptor control of the homeostatic adaptation to $\mathrm{AH}$.

\section{Results}

Loss of CHL1 increases the survival rate after $\mathrm{AH}$. In our previous study, we found that the expression of $\mathrm{CHL} 1$ was decreased in the cerebral cortex, hypothalamus, and brain stem and increased in the cerebellum after the induction of $\mathrm{AH}$. Thus, we hypothesized that $\mathrm{CHL} 1$ may be involved in the regulation of the hypoxic response in vivo. To address this possibility, $\mathrm{CHL} 1^{-/-}$mice and wild-type littermates were subjected to hypoxia $\left(5 \% \mathrm{O}_{2}\right)$ for $10 \mathrm{~min}$. We found that $\mathrm{CHL}^{-1-}$ mice showed a dramatically decreased mortality rate after they were subjected to $\mathrm{AH}$ (survival rate: $62.5 \%$ in $\mathrm{CHL}^{-1-}$ versus $12.5 \%$ in wild-type) (Figure 1a). The survival time after $\mathrm{AH}$ was $343.3 \pm 51.9 \mathrm{~s}$ for $\mathrm{CHL} 1^{+/+}$mice and $403.2 \pm 35.9 \mathrm{~s}$ for $\mathrm{CHL}^{-1-}$ mice $(P=0.0173$, Figure $1 \mathrm{~b})$. To further investigate the above findings, $\mathrm{CHL}^{-1-}$ mice and $\mathrm{CHL}^{+/+}$littermates generated from breeding $\mathrm{CHL}^{+/-}$ mice were treated with hypobaric hypoxia for $15 \mathrm{~min}$. Again, we observed an increased survival rate in $\mathrm{CHL}^{-1-}$ mice ( $86 \%$ versus $13.4 \%$ in wild-type, $P=0.0019$, Figures $1 c$ and d). Thus, $\mathrm{CHL}^{-1}$ mice exhibited lower mortality compared with wild-type mice after exposure to $\mathrm{AH}$.

$\mathrm{CHL1}^{-1-}$ mice exhibit an augmented ventilatory response to hypoxia. To further understand why the loss of $\mathrm{CHL} 1$ results in an increased survival rate after $\mathrm{AH}$, we observed the changes in respiration of mice upon exposure to hypoxia. Six- to eight-week-old unanesthetized male $\mathrm{CHL}^{+/+}$and $\mathrm{CHL}^{-1-}$ mice were exposed to $10 \% \mathrm{O}_{2}$ $(15 \mathrm{~min})$ and $5 \% \mathrm{O}_{2}(15 \mathrm{~min})$, and the respiratory rate $(\mathrm{RR})$ and tidal volume $\left(\mathrm{V}_{\mathrm{T}}\right)$ were continuously monitored using whole-body plethysmography. The ventilation during normoxia $\left(21 \% \mathrm{O}_{2}\right)$ was similar between the $\mathrm{CHL}^{-/-}$and $\mathrm{CHL}^{+/+}$groups. When the $\mathrm{O}_{2}$ content of the inspired air was dropped to $10 \%$, the breathing rate accelerated, whereas $V_{T}$ remained unaltered in both groups of mice. The peak increase in minute ventilation upon exposure to $10 \% \mathrm{O}_{2}$ was not significantly different between $\mathrm{CHL}^{-/-}$and
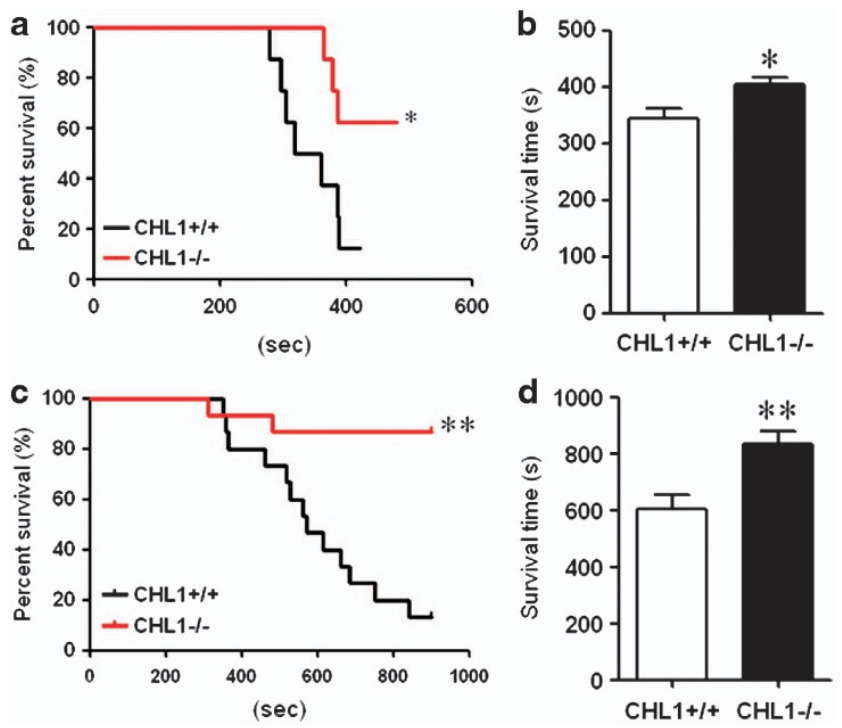

Figure $1 \mathrm{CHL} 1$ deficiency enhances the survival rate and survival time of mice subjected to $\mathrm{AH}$. (a) Kaplan-Meier curves show a significant difference in survival rates between $\mathrm{CHL} 1^{+/+}$and $\mathrm{CHL}^{-1-}$ mice subjected to $\mathrm{AH}$. (b) $\mathrm{CHL}^{-1-}$ mice show a significant increase in survival time after $\mathrm{AH}\left(n=8,{ }^{*} P<0.05\right)(\mathbf{c})$ Kaplan-Meier curves show a significant difference in survival rates between $\mathrm{CHL} 1^{+/+}$and $\mathrm{CHL}^{-1-}$ mice subjected to acute hypobaric hypoxia (AHH). (d) $\mathrm{CHL} 1^{-1-}$ mice show a significant increase in survival time after $\mathrm{AHH}\left(n=20,{ }^{\star \star} P<0.01\right)$ 
$\mathrm{CHL}^{+1+}$ mice. As the $\mathrm{O}_{2}$ content in inspired air was further dropped to $5 \%$, the $\mathrm{CHL}^{+1+}$ mice responded with an increase in $\mathrm{V}_{\mathrm{T}}$ but with no further increase in breathing rate, whereas the $\mathrm{CHL}^{-1-}$ mice responded with an increase in both $\mathrm{V}_{\mathrm{T}}$ and breathing rate. Consequently, the minute ventilation increased to a significantly greater extent in $\mathrm{CHL}^{-1-}$ mice than in the wild-type counterparts (Figures $2 a-c)$. We further analyzed the oxygen saturation level in the mice during normoxia and hypoxia. The blood oxygen saturation levels during normoxia were not significantly different between the two groups. However, oxygen saturation at 10 and $15 \mathrm{~min}$ after exposure to hypoxia $\left(5 \% \mathrm{O}_{2}\right)$ was significantly greater in $\mathrm{CHL}^{-/}$mice $(77.4 \pm 10.4$ and $70.3 \pm 11.2)$ than in $\mathrm{CHL}^{+/+}$mice $(72.4 \pm 11.5$ and $64.1 \pm 4.4$ ) (see Table1). These results indicate that $\mathrm{CHL} 1$ deficiency augments the ventilatory response to $\mathrm{AH}$.

To confirm whether the increased respiratory response in the $\mathrm{CHL} 1^{-/}$mice is specific to hypoxia, we examined the respiratory response to hypercapnia. We monitored respiration in response to hypercapnia $\left(21 \% \mathrm{O}_{2}+5 \% \mathrm{CO}_{2}\right.$ and $21 \%$ $\mathrm{O}_{2}+3 \% \mathrm{CO}_{2}$ ). Hypercapnia induced a profound increase in ventilation in all groups of animals. However, there were no significant differences in ventilation $\left(R R, V_{T}\right.$, and $\left.V_{E}\right)$ between $\mathrm{CHL}^{-1-}$ and $\mathrm{CHL} 1^{+/+}$mice when the concentration of $\mathrm{CO}_{2}$ in the inspired air was increased to $3 \%$ and then to $5 \%$
(Figures 2d-f). These results demonstrate that $\mathrm{CHL} 1$ deficiency does not affect the ventilatory responses to hypercapnia.

Expression and localization of CHL1 in the CB. The primary site of oxygen sensing is the $C B$, which can instantaneously sense changes in the composition of the arterial blood, and the afferent signal is relayed to the brain stem to stimulate the respiratory center (and to counteract the direct inhibitory effects of hypoxia on respiratory center) to produce hyperventilation. The $\mathrm{CB}$, a small neural crest-derived paired organ located at the carotid bifurcation, is composed of clusters of neuron-like glomus or type-I cells enveloped by glia-like sustentacular or type-II cells. ${ }^{16}$ To investigate the role of $\mathrm{CHL} 1$ in this peripheral chemoreceptor, CBs were sectioned and analyzed by immunofluorescence staining. Strong CHL1 immunofluorescence was seen surrounding the immunofluorescence for tyrosine hydroxylase (TH), an established marker of glomus cells (Figure $3 \mathrm{~A}$ ). The staining pattern suggests that CHL1 is primarily localized to type-II cells or afferent terminals. To further study the localization of CHL1, the CBs of adult mice were isolated, enzymatically dissociated, and then cultured as previously described. ${ }^{16}$ The cultured CB cells are primarily composed of clusters of neuron-like glomus (TH-positive
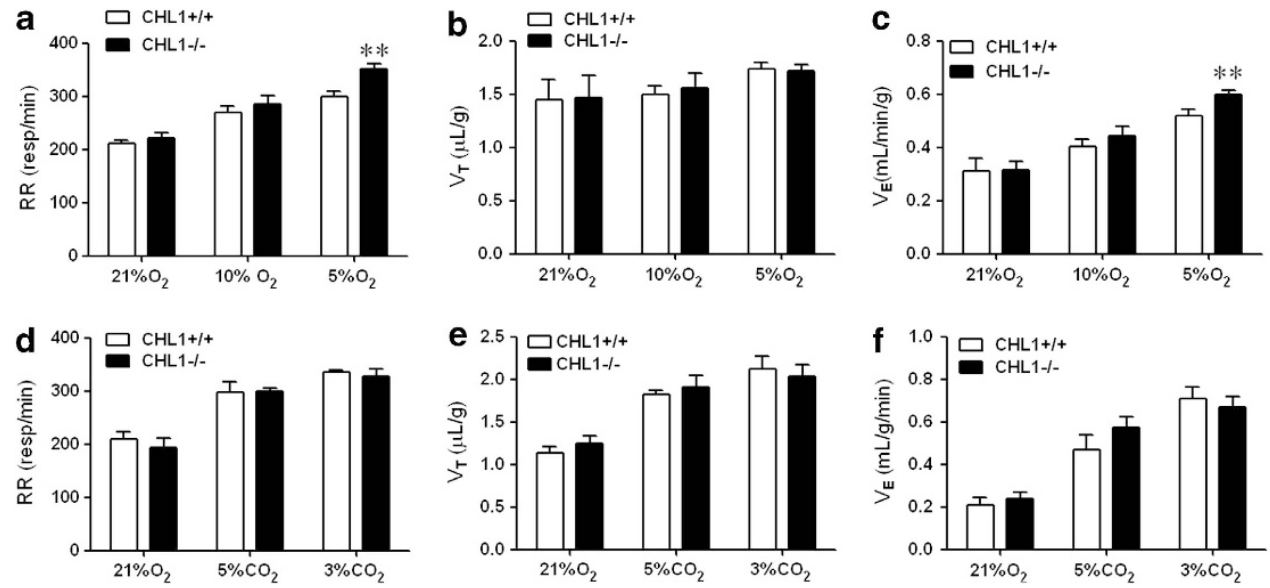

Figure 2 Ventilatory responses to hypoxia and hypercapnia in $\mathrm{CHL} 1^{+1+}$ and $\mathrm{CHL} 1^{-1-}$ mice. $\mathrm{RR}, \mathrm{V}_{\mathrm{T}}$, and $\mathrm{V}_{\mathrm{E}}$ were measured in unanesthetized mice by whole-body plethysmography in normoxia $\left(21 \% \mathrm{O}_{2}\right)$, hypoxia $\left(10 \% \mathrm{O}_{2}, 5 \% \mathrm{O}_{2}\right)$, and hypercapnia $\left(5 \% \mathrm{CO}_{2}, 3 \% \mathrm{CO}_{2}\right)$ conditions. The average values of $\mathrm{RR}, \mathrm{V}_{\mathrm{T}}$, and $\mathrm{V}_{\mathrm{E}}$ in response to $10 \%$ $\mathrm{O}_{2}, 5 \% \mathrm{O}_{2}$ hypoxia are shown in (a-c) and in response to $5 \% \mathrm{CO}_{2}, 3 \% \mathrm{CO}_{2}$ hypercapnia are shown in (d-f). Data shown are the mean \pm S.E.M. from eight mice in each group. ${ }^{* *} P<0.01$ compared with the $\mathrm{CHL} 1^{+1+}$ group in response to hypoxia

Table1 Measurement of physiological parameters before and after acute hypoxia (15 min)

\begin{tabular}{|c|c|c|c|c|c|}
\hline \multirow[t]{2}{*}{ Parameters } & \multirow[t]{2}{*}{ Genotype } & \multirow[t]{2}{*}{ Normoxia $\left(20 \% \mathrm{O}_{2}\right)$} & \multicolumn{3}{|c|}{ Exposure to hypoxia $\left(5 \% \mathrm{O}_{2}\right)$} \\
\hline & & & $5 \mathrm{~min}$ & $10 \mathrm{~min}$ & $15 \mathrm{~min}$ \\
\hline $\mathrm{SaO}_{2}(\%)$ & $\begin{array}{l}\text { Wild-type } \\
\text { CHL1-/- }\end{array}$ & $\begin{array}{l}96.9 \pm 1.8 \\
98.4 \pm 0.8\end{array}$ & $\begin{array}{l}87.7 \pm 14.0 \\
89.2 \pm 10.7\end{array}$ & $\begin{array}{l}72.4 \pm 11.5 \\
77.4 \pm 10.4\end{array}$ & $\begin{array}{l}64.1 \pm 4.4^{\star *} \\
70.3 \pm 11.2^{\star *}\end{array}$ \\
\hline HR (b.p.m.) & $\begin{array}{l}\text { Wild-type } \\
\text { CHL1-/- }\end{array}$ & $\begin{array}{l}239.4 \pm 14.2 \\
216.2 \pm 13.7\end{array}$ & $\begin{array}{l}250.8 \pm 11.9 \\
228.5 \pm 14.1\end{array}$ & $\begin{array}{l}261.5 \pm 13.4 \\
236.8 \pm 14.8\end{array}$ & $\begin{array}{l}263.9 \pm 13.2^{*} \\
245.5 \pm 13.2^{*}\end{array}$ \\
\hline BR (b.r.p.m.) & $\begin{array}{l}\text { Wild-type } \\
\text { CHL1 }-/-\end{array}$ & $\begin{array}{l}77.2 \pm 10.2 \\
73.2 \pm 5.7\end{array}$ & $\begin{array}{l}84.5 \pm 8.3 \\
79.3 \pm 10.3\end{array}$ & $\begin{array}{l}82.1 \pm 7.4 \\
84.1 \pm 9.2\end{array}$ & $\begin{array}{l}83.3 \pm 10.6^{*} \\
86.6 \pm 11.2^{*}\end{array}$ \\
\hline
\end{tabular}


cells) cells and are enveloped by glia-like sustentacular (GFAP and nestin-positive cells) cells (Figure 3B). Strong immunofluorescence for CHL1 was identified in $\mathrm{GFAP}^{+}$ sustentacular cells and, moderate CHL1 immunostaining was also observed in $\mathrm{TH}^{+}$glomus cells (Figure $3 \mathrm{C}$ ).

We then investigated whether the expression of $\mathrm{CHL} 1$ would be altered in mice that were subjected to prolonged hypoxia. CHL1 protein levels in the CB were determined by western blot. The levels of $\mathrm{CHL} 1$ expression were significantly decreased in mice exposed to hypoxia $\left(8 \% \mathrm{O}_{2}\right)$ for $8 \mathrm{~h}$ compared with those exposed to normoxia (Figures 3D and E). These results suggest that $\mathrm{CHL1}$ expression in the chemoreceptive $\mathrm{CB}$ is altered in response to hypoxia.

CHL1 deficiency enhances the $\mathrm{CB}$ response to hypoxia in mice. The $\mathrm{CB}$ senses changes in arterial $\mathrm{PO}_{2}$ during $\mathrm{AH}$ and converts the hypoxic stimulus to afferent nerve activation. Then, the increased sensory discharge is transmitted to the central nervous system, which in turn triggers appropriate cardio-respiratory responses, including a stimulation of breathing and a rise in blood pressure. ${ }^{17-19}$ The hypoxic ventilatory response represents a major adaptive reflex triggered by the $\mathrm{CB}$. We next examined whether CHL1 deficiency would alter the response of $\mathrm{CB}$ to hypoxia. Chemoreceptive afferent nerve activity was recorded in the ex vivo $\mathrm{CB} /$ sinus nerve preparations taken from $\mathrm{CHL}^{-/-}$mice and wild-type littermates under normoxia and hypoxia conditions. There were no significant differences in the baseline sinus nerve discharge between $\mathrm{CHL}^{-1-}$ and wild-type littermates under normoxia condition. When the superfusion solution was switched to the hypoxic solution $\left(5 \% \quad \mathrm{O}_{2}\right.$, for $\left.5 \mathrm{~min}\right)$, sinus nerve discharge markedly increased in both groups (Figure $4 a$ ). The magnitude of hypoxia-induced afferent response, however, was significantly greater in $\mathrm{CHL}^{-/-}$than in wild-type preparations. The afferent discharge rate increased from $11.7+2.11$ to a peak of $340.32 \pm 70.32$ spikes/s in $\mathrm{CHL}^{-1}{ }^{-1}$ preparations $(n=6)$ as compared with an increase from $10.2 \pm 1.72$ spikes/s to a peak of $171.82 \pm 20.79$ spikes/ $\mathrm{s}(n=6)$ in wild-type mice $(P<0.05$, Figure $4 \mathrm{c})$. We further investigated the sinus nerve activity in response to $15 \mathrm{~min}$ of continuous hypoxia and found that the afferent response in $\mathrm{CHL}^{-1}$ preparations was also significantly increased compared with wild-type preparations (Figures $4 b-d$ ).

\section{A}
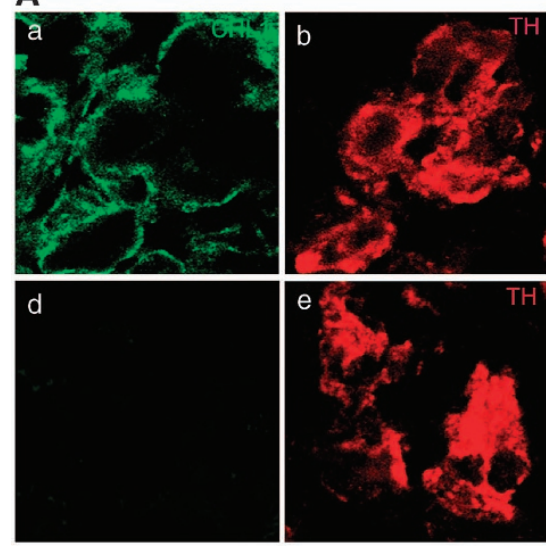

C
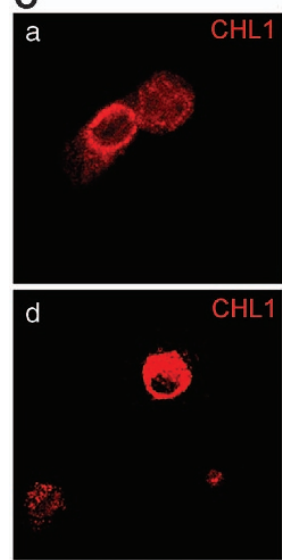
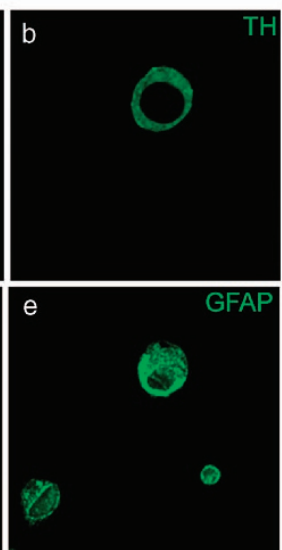
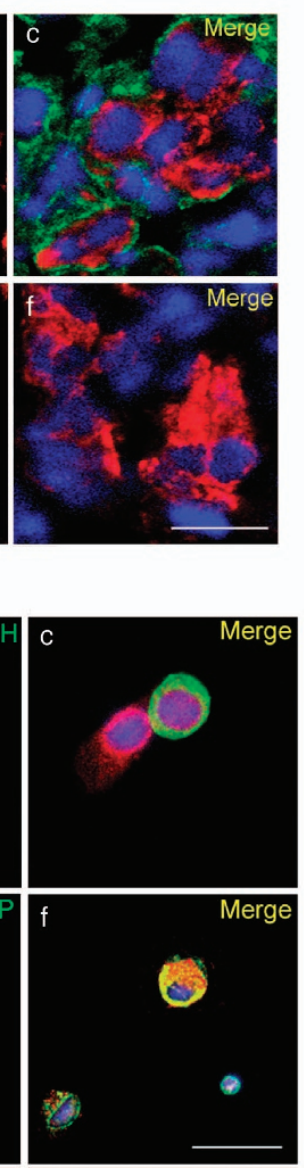

B
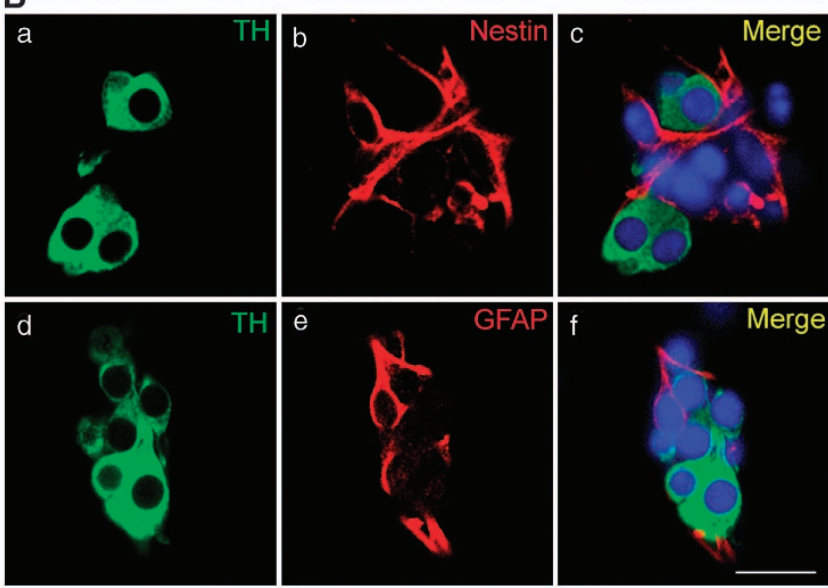

D
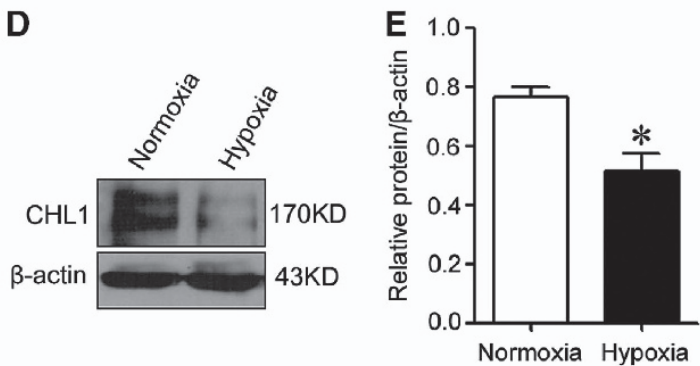

Figure $3 \mathrm{CHL} 1$ localization in the mouse $\mathrm{CB}$. (A) CHL1 expression in CBs. CB sections were stained with antibodies specific against CHL1 (green) and TH, a marker of glomus cells (red). (B) The cultured CB cells are primarily composed of clusters of $\mathrm{TH}^{+}$cells (a-d) and enveloped by GFAP ${ }^{+}$(b) and nestin ${ }^{+}$(e) cells. (C) CHL1 expression in cultured glomus cells. CHL1 (red) colocalized with $\mathrm{TH}^{+}$(green) glomus cells (a-c) and GFAP ${ }^{+}$(green) sustentacular cells (d-f) in cultured CB cells. Scale bar: $20 \mu$ m. (D) Immunoblot assays of CHL1 protein from mouse CBs in response to hypoxia. (E) Quantitative analysis of CHL1 protein expression in response to hypoxia. Data are presented as the mean \pm S.E.M. from five experiments. ${ }^{*} P<0.05$ compared with control normoxic mice 

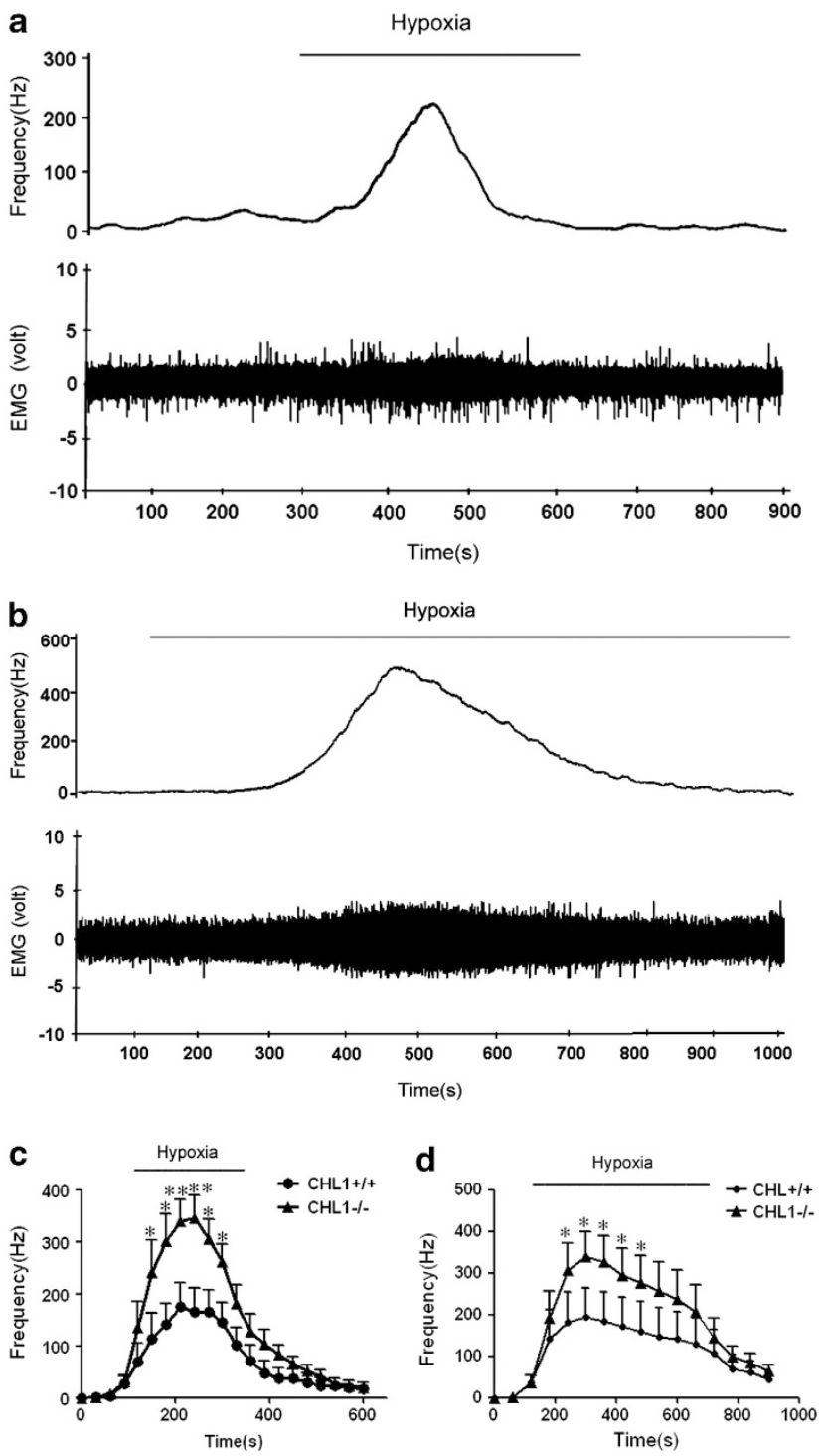

Figure 4 Recording of the afferent nerve responses to hypoxia in the isolated $\mathrm{CB}$-sinus nerve preparation taken from $\mathrm{CHL} 1^{+/+}$and $\mathrm{CHL}^{-1-}$ mice. (a) Representative recording of the afferent nerve response to hypoxia in $\mathrm{CHL} 1^{+/+}$mice. (b) Representative recording of the afferent nerve response to hypoxia in $\mathrm{CHL}^{-/-}$mice. (c) Average data showing the sinus nerve discharge of the $\mathrm{CB}$ from $\mathrm{CHL}^{+l+}$ and $\mathrm{CHL}^{-l-}$ mice exposed to hypoxia $(5 \mathrm{~min})$. (d) Average data showing the sinus nerve discharge of the $\mathrm{CB}$ from $\mathrm{CHL}^{+1+}$ and $\mathrm{CHL}^{-/-}$mice exposed to hypoxia (15 min). Data presented are the mean \pm S.E.M. from eight mice in the $\mathrm{CHL} 1^{+i+}$ control and the $\mathrm{CHL} 1{ }^{-l}-$ group. ${ }^{*} P<0.05$, ${ }^{* *} P<0.01$ compared with control CBs

CHL1 deficiency leads to hyperplasia of the CB. The glomus cells in the $\mathrm{CB}$ are considered to be the primary hypoxia-sensing cells, and a reduction in the oxygen supply activates glomus cells, resulting in membrane depolarization and release of neurotransmitters such as ATP, acetylcholine, and dopamine. ${ }^{20-22}$ Long-term exposure to low-oxygen environments (such as during acclimation to high altitudes) results in a dramatic increase in the number of glomus cells and in $\mathrm{CB}$ size. ${ }^{23}$ To further understand the potential role of
$\mathrm{CHL1}$ in $\mathrm{CB}$ development, a morphological analysis of the $\mathrm{CBs}$ from $\mathrm{CHL} 1^{-/-}$and $\mathrm{CHL} 1^{+/+}$mice was performed. The CBs, nestled at the bifurcation of the internal and external carotid arteries, were removed, fixed in $4 \%$ paraformaldehyde, and sectioned for immunohistochemical staining. $\mathrm{CHL1}^{-1-}$ exhibited a 1.3-fold-enlarged volume of the $\mathrm{CB}$ and an increased number of glomus cells when compared with $\mathrm{CHL}^{+/+}$mice (Figures $5 \mathrm{~B}$ and $\mathrm{C}$ ). However, a difference in the volume of $\mathrm{CB}$ between $\mathrm{CHL}^{-/-}$mice and $\mathrm{CHL} 1^{+/+}$mice was not apparent until 14 days after hypoxia (see Supplementary Figure 1). We further studied the expression of $\mathrm{TH}$, a glomus celltype-specific marker, in the $\mathrm{CB}$ using western blot analysis. The level of $\mathrm{TH}$ expression in $\mathrm{CHL}^{-/}$mice was increased when compared with $\mathrm{CHL}^{+/+}$mice; however, nestin (a marker of multipotent cells) and GFAP (a marker of sustentacular cells) expressions were not different between these two groups (Figures $5 \mathrm{E}-\mathrm{G}$ ). These results demonstrate that $\mathrm{CHL} 1$ negatively regulates the number of glomus cells in the $\mathrm{CB}$ and may be involved in the regulation of $\mathrm{CB}$ activity.

Blood pressure and catecholamine levels in $\mathrm{CHL1}^{-1-}$ mice under hypoxia. In addition to hyperventilation in response to hypoxia, increased $\mathrm{CB}$ activity also causes enhanced sympathetic activation and a cardiovascular response. ${ }^{14,21}$ We therefore examined whether there were differences in arterial blood pressure and plasma catecholamine levels between $\mathrm{CHL}^{-1-}$ mice and the wild-type littermates. Arterial blood pressure was determined using the tail-cuff method during plesthysmography under normoxic and hypoxic conditions. Mean blood pressure was higher in $\mathrm{CHL1}{ }^{-1-}$ mice than in wild-type mice, as were systolic and diastolic pressures (Figures $6 \mathrm{a}-\mathrm{c}$ ). Plasma NE and dopamine levels were also significantly higher in $\mathrm{CHL}^{-/-}$mice. Unexpectedly, the blood pressure did not alter significantly during hypoxia in either group of mice. However, plasma norepinephrine dropped in $\mathrm{CHL}^{-/-}$mice $(P=0.09)$ and remained unchanged in wild-type mice. Epinephrine and dopamine levels were similarly increased in $\mathrm{CHL}^{-1-}$ compared with wild-type mice during hypoxia. Thus, it appears that $\mathrm{CHL} 1^{-1-}$ mice manifested an ongoing hyperactive sympathetic nervous system.

\section{Discussion}

The present study reveals a novel physiological role for the cell adhesion molecule $\mathrm{CHL} 1$ in the $\mathrm{CB}$. We found that CHL1 is expressed within the $\mathrm{CB}$, the major peripheral chemoreceptor that initiates the homeostasis adaptation to hypoxia. CHL1 deficiency results in hyperplasia of type-I glomus cells, upregulated $\mathrm{TH}$ expression, and enhanced carotid sinus nerve activity in response to $\mathrm{AH}$. Concomitantly, $\mathrm{CHL}^{-1-}$ mice manifested increased ventilatory responses and lower mortality following $\mathrm{AH}$. These results reveal a previously unappreciated role of CHL1 in the regulation of the homeostasis responses to hypoxia.

One of the major findings of the current study is that $\mathrm{CHL} 1^{-/-}$mice had a greater survival rate during hypoxia. Interestingly, a recent study reported that BACE $1^{-1}$ mice were more susceptible to seizures upon exposure to $\mathrm{AH}$ 


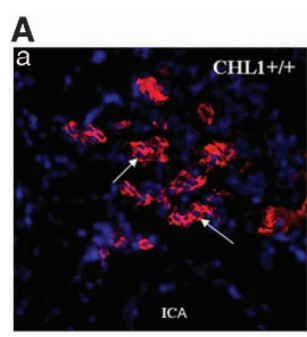

D

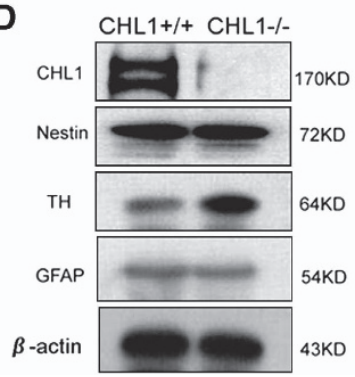

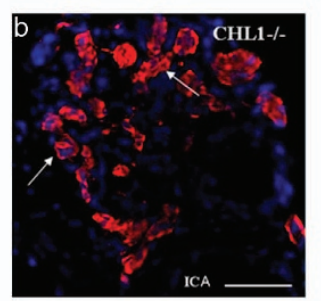

E

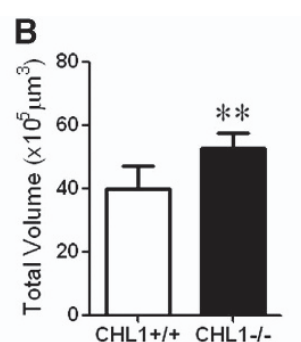

$\mathbf{F}$

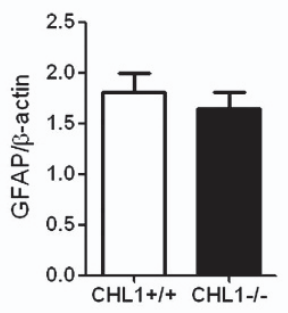

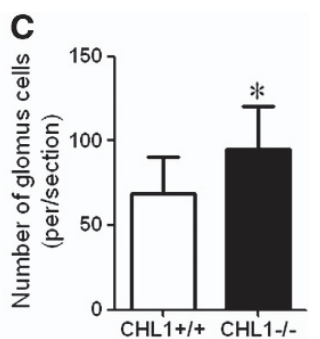

G

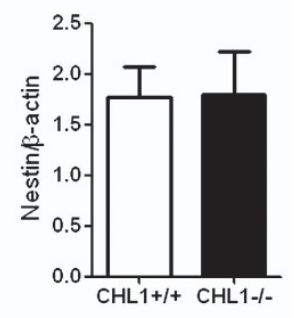

Figure 5 Morphological analysis of the $\mathrm{CBs}$ from $\mathrm{CHL}^{-1-}$ mice. (A) Representative photomicrographs of $\mathrm{CB}$ sections were stained with antibodies specific for TH in $\mathrm{CHL}^{-1-}$ (b) and $\mathrm{CHL} 1^{+/+}$(a) mice. (B) Statistical analysis of the volume of $\mathrm{CBs}$ in $\mathrm{CHL} 1^{+/+}$and $\mathrm{CHL} 1^{-1-}$ mice. $\mathrm{CHL} 1^{-/-}$mice exhibit an enlarged CB volume. (C) Statistical analysis of the number of glomus cells in $\mathrm{CHL} 1^{+/+}$and $\mathrm{CHL} 1^{-1-}$ mice. $\mathrm{CHL} 1^{-1-}$ mice exhibited an increased volume of glomus cells compared with $\mathrm{CHL} 1^{+/+}$ mice. (D) Western blot analysis of the cell-type-specific marker protein in $\mathrm{CHL} 1^{+1+}$ and $\mathrm{CHL}^{-1}-\mathrm{CBs}$. (E and $\mathbf{F}$ ) The relative intensity of marker expression compared with $\beta$-actin. The expression of TH in $\mathrm{CHL} 1^{-1-}$ mice was increased compared with $\mathrm{CHL} 1^{+/+}$controls. Data are presented as the mean \pm S.E.M. from 10 mice in each group. ICA, internal carotid artery. $(\mathrm{E}-\mathrm{G})$ The relative intensity of marker expression compared with $\beta$-actin. Expression of $\mathrm{TH}$ in $\mathrm{CHL} 1^{-1-}$ mice was increased compared with $\mathrm{CHL} 1^{+1+}$ controls. Data are presented as the means \pm SEM from 10 mice in each group. ICA, internal carotid artery. ${ }^{\star} P<0.05,{ }^{* *} P<0.01$ compared with control CBs
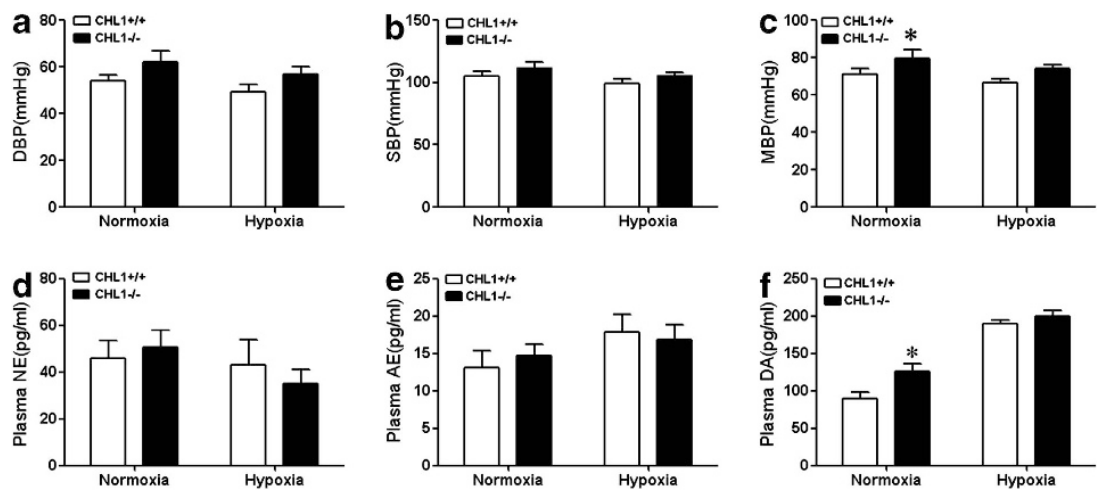

Figure 6 Blood pressure and plasma catecholamine levels in $\mathrm{CHL} 1^{-1}-$ mice under hypoxia. (a-c) Statistical analysis of mean (MBP), systolic (SBP), and diastolic (DBP) blood pressure levels in $\mathrm{CHL} 1^{+/+}$and $\mathrm{CHL} 1^{-/-}$mice under hypoxia. (d-e) Statistical analysis of plasma catecholamine levels in $\mathrm{CHL} 1^{+/+}$and $\mathrm{CHL} 1^{-1-}$ mice under hypoxia. Data are presented as the mean \pm S.E.M. from 10 mice in each group. (d-f) Statistical analysis of plasma catecholamine levels in $\mathrm{CHL} 1^{+/+}$and $\mathrm{CHL} 1^{-I-}$ mice under hypoxia. Data are presented as the means \pm S.E.M. from 10 mice in each group. ${ }^{*} P<0.05,{ }^{* \star} P<0.01$ compared with control mice

$\left(5 \% \mathrm{O}_{2}\right)$. In that study, $\sim 60 \%$ of BACE1 ${ }^{-/-}$mice died during a 12-min ischemic insult compared with no deaths in the wildtype group. CHL1 was shown to be a physiological substrate of BACE1, and the level of CHL1 expression was elevated in BACE $1^{-1-}$ mice. $^{24}$ These data together support a novel role for $\mathrm{CHL} 1$ in acute hypoxic stress.

Survival of mammals in an acute hypoxic state requires fast respiratory and cardiovascular adjustments to ensure sufficient oxygen supply to tissues, particularly to the brain, which is highly vulnerable to lack of $\mathrm{O}_{2} \cdot{ }^{25}$ The chemoreceptive $\mathrm{CB}$ detects oxygen availability and triggers the adaptative responses to hypoxic conditions. In this regard, a drop in arterial $\mathrm{PO}_{2}$ leads to an increase in sensory discharge of the
CBs in all mammalian species, and the increased sensory activity is transmitted to the central nervous system, which in turn triggers appropriate autonomic changes, including stimulation of breathing, sympathetic activation, and a rise in blood pressure. ${ }^{26}$ If the CB dysfunction occurs in patients with ischemia or hypoxia-related illness, then impaired sensitivity to hypoxia and further failure to reduce metabolic oxygen demand in conditions of low $\mathrm{O}_{2}$ might promote mortality. ${ }^{22,23,27}$ Hence, the $\mathrm{CB}$ has a major role sustaining homeostasis in hypoxic conditions.

Previously, it was shown that an enlarged CB with clusters of $\mathrm{TH}^{+}$glomus cells is the typical histological appearance of CBs exposed to hypoxia. ${ }^{16,23}$ Here we show that CHL1 
deletion is also sufficient to induce hyperplasia of the $C B$ characterized by increased $C B$ mass, increased number of glomus cells, and upregulated TH expression. The increased number of glomus cells leads to the release of more neurotransmitters, which then induced a greater afferent nerve discharge in $\mathrm{CHL}^{-/-}$mice compared with the $\mathrm{CHL}^{+/+}$mice. Consistent with the morphological phenotype, the $\mathrm{CB}$ of $\mathrm{CHL} 1$-deficient mice had an augmented chemosensory response as determined by the sinus nerve activity. Hypoxia induces release of neurotransmitters from CB chemoreceptor cells that increases the activity of afferent chemosensory fibers. ${ }^{28}$ The increased ventilation and sympathy-excitation triggered by hypoxia in the CHL1deficient mice represent the important homeostasis responses for mammalian adaptation to acute hypoxic environments. Concomitantly, the mice manifested augmented respiratory adaptation and greater survival rate following $\mathrm{AH}$. It is tempting to assume that the augmented respiratory adaptation partially underlies the improved survival during hypoxic conditions.

Indeed, the increase in the vital capacity and breath rate is critical for the inspiration of more oxygen to prevent a decrease in blood oxygen saturation $\left(\mathrm{SaO}_{2}\right)$ and to maintain normal function of the body during hypoxia. Consistently, the blood oxygen saturation at 10 and $15 \mathrm{~min}$ after exposure to hypoxia $\left(5 \% \mathrm{O}_{2}\right)$ was significantly greater in $\mathrm{CHL}^{-/-}$mice $(77.4 \pm 10.4$ and $70.3 \pm 11.2)$ than in $\mathrm{CHL}^{+/+}$mice $(72.4 \pm 11.5$ and $64.1 \pm 4.4)$, whereas there were no differences between the two groups during the normoxia condition.

On the other hand, upon exposure to $\mathrm{AH}$, the glomus cell membrane depolarization by inhibition of $\mathrm{O}_{2}$-sensitive $\mathrm{K}^{+}$ channels induces extracellular $\mathrm{Ca}^{2+}$ influx and then leads to a reversible release of neurotransmitters that activate afferent nerve fibers. ${ }^{12}$ In the current study, we confirmed CHL1 expression in the CB and primary distribution in type II cells as well as afferent terminals, although type I glomus (the oxygensensing cells) also appeared to express a lower level of CHL1 through immunofluorescence. Importantly, we found that CHL1 expression in the CB was decreased following $8 \mathrm{~h}$ of hypoxia $\left(8 \% \mathrm{O}_{2}\right)$, and hypoxia induced a significantly greater afferent nerve discharge in $\mathrm{CHL}^{-1-}$ mice compared with $\mathrm{CHL}^{+/+}$mice. One possible reason is that $\mathrm{CHL} 1$ may also be involved in the regulation of synaptic vesicle exo- and endocytosis, as recent work has shown a novel role for CHL1 as a co-chaperone in the presynaptic chaperone machinery consisting of Hsc70, CSP, and aSGT. ${ }^{29}$ The interactions between $\mathrm{CHL} 1$-containing chaperones and proteins of the synaptic vesicle fusion machinery are involved in the regulation of synaptic vesicle recycling following prolonged and stressful synapse activity. ${ }^{30} \mathrm{CHL} 1$ deficiency results in enhanced susceptibility of syntaxin 1B, SNAP25, and VAMP2 to degradation, especially under stressful conditions, such as exposure to heat or prolonged synaptic activity. ${ }^{29}$ Therefore, whether $\mathrm{CHL} 1$ interacts with the synaptic chaperone and mediates the synaptic vesicle exocytosis or endocytosis in glomus cells is an interesting question and needs to be further addressed.

In addition, $\mathrm{CHL} 1^{-/}$mice had higher blood pressure and plasma catecholamine levels under normoxic conditions, indicative of a greater sympathetic tone, compared with wild-type mice. The significant difference in plasma dopamine levels between $\mathrm{CHL} 1^{-/-}$and wild-type mice would suggest greater activation of the sympathetic nerve-adrenal gland axis. The lower heart rate seen in $\mathrm{CHL}^{-1}{ }^{-}$mice might be due to the influence of the arterial baroreceptor-vagal reflex. At present, however, the possibility that an enhanced chemosensory activity in the $\mathrm{CB}$ underlies the greater sympathetic tone in $\mathrm{CHL}^{-1-}$ mice has yet to be explored. We also attempted to compare the sympathetic outflow in $\mathrm{CHL1}^{-1-}$ and wild-type mice following $\mathrm{AH}$. Intriguingly, plasma NE, epinephrine and dopamine levels and blood pressure were not significantly different between $\mathrm{CHL}^{-1-}$ and wild-type mice following $\mathrm{AH}$ ( $5 \% \mathrm{O}_{2}$ for $\left.15 \mathrm{~min}\right)$. The results might suggest a dynamic change in the sympathetic limb of the arterial chemoreceptor reflexes in CHL1-deficient mice, which awaits further investigation.

However, even a subtle influence on CB function may lead to significant changes in homeostatic adaptation in hypoxic states. Our data provide evidence that the cell adhesion molecule $\mathrm{CHL} 1$ is involved in the regulation of respiration during acute hypoxic stress and affects the survival rate. Targeting cell adhesion molecules may be developed as a potential mode of treatment against, or for the prevention of, various hypoxia-related diseases. Future studies will continue to investigate the role of CHL1 in chronic hypoxia-related diseases, such as brain ischemia or heart failure, to confirm whether this protective effect is applicable to hypoxia-related diseases.

\section{Materials and Methods}

Animals. The generation of a $\mathrm{CHL} 1$-deficient $\left(\mathrm{CHL}^{-1-}\right)$ mouse in the $\mathrm{C} 57 \mathrm{BL} / 6$ genetic background has been described previously. ${ }^{7}$ Heterozygous mice were mated to generate wild-type $\left(\mathrm{CHL} 1^{+1+}\right)$ and knockout $\left(\mathrm{CHL}^{-1-}\right)$ pairs, and littermates were used in all experiments. Genotyping was performed using tail DNA analysis. All experiments were performed on 2-month-old male $\mathrm{CHL} 1^{+1+}$ and $\mathrm{CHL}_{1}{ }^{-1}$ mice (22-25 g body weight). Mice were maintained at the animal facility with free access to water and food in accordance with institutional guidelines. The Institutional Animal Care and Use Committee (IACUC) of the Academy of Beijing medical Sciences approved all experiments involving mice.

Immunofluorescence. The carotid bifurcation was fixed in $4 \%$ paraformaldehyde, and $10 \mu \mathrm{m}$ serial sections were cut using a Thermo Cryotome. Sections were incubated for $30 \mathrm{~min}$ at room temperature in a block solution (10\% normal horse serum, $1 \%$ BSA, $0.1 \%$ TritonX-100 in PBS). Sections were then incubated overnight at $4{ }^{\circ} \mathrm{C}$ with the following primary antibodies: mouse anti-rat $\mathrm{CHL} 1$ (1:500; R\&D Systems, Minneapolis, MN, USA), rabbit anti-rat TH (1:2000; Millipore, Billerica, MA ,USA) or mouse anti-rat Nestin (1:500; Millipore) or rabbit anti-rat GFAP (1:1000; DAKO, Produktionsvej, Denmark). The immunoreactivity was visualized with Alexa Fluor 488- or 594-conjugated secondary antibodies (Molecular Probes). Nuclei were counterstained with DAPI-containing mounting medium (Vector Laboratories, Burlingame, CA, USA). Fluorescence was visualized using a Zeiss LSM5 confocal laser-scanning microscope.

Dissociation of glomus cells. CBs were removed from anesthetized young adult mice. ${ }^{24-28}$ They were then dissected and placed on ice-cold Tyrode solution $\left(\mathrm{Ca}^{2+}\right.$ and $\mathrm{Mg}^{2+}$ free) and then incubated for $30 \mathrm{~min}$ at $37^{\circ} \mathrm{C}$ in an enzyme solution containing collagenase and trypsin in a $\mathrm{CO}_{2}$ incubator. Finally, the cells were mechanically dispersed. Cell density was determined using a hemocytometer (Millipore). For direct staining of dispersed cells they were plated onto an adherent substrate for $1 \mathrm{~h}$, then fixed in $4 \%$ PFA, and stained following the same procedures used in the immunofluorescence staining.

CB sensory activity. Sensory activity from CBs ex vivo was recorded as described. ${ }^{31}$ Briefly, CBs along with the sinus nerves were harvested from anesthetized mice, placed in a recording chamber, and superfused with oxygenated 
Kreb's solution ( $140 \mathrm{mM} \mathrm{NaCl}, 2.7 \mathrm{mM} \mathrm{KCl}, 2.5 \mathrm{mM} \mathrm{CaCl}_{2}, 0.5 \mathrm{mM} \mathrm{MgCl}_{2}, 5.5 \mathrm{mM}$ Hepes, $11 \mathrm{mM}$ D-glucose and $5 \mathrm{~mm}$ sucrose; $21 \% \mathrm{O}_{2}+5 \% \quad \mathrm{CO}_{2}+74 \% \mathrm{~N}_{2}$ ). The sinus nerve was carefully dissected and recorded using a suction electrode. Nerve signal was amplified and filtered using the Neurolog system (Digitimer Ltd, Cambridge, UK), A/D converted (Micro1401, Cambridge Electronic Design, Cambridge, UK), and processed using the Spike2 data capture and analysis program (CED, Cambridge, UK). The preparation was allowed to stabilize for about $30 \mathrm{~min}$ and was then intermittently challenged with hypoxic solutions (Krebs bubbled with $5 \% \mathrm{O}_{2}+5 \% \mathrm{CO}_{2}+90 \% \mathrm{~N}_{2}$ ). Hypoxic duration was for 5 or $15 \mathrm{~min}$.

Whole-body plethysmography. Ventilation was monitored using a whole-body plethysmograph in anesthetized mice. Baseline ventilation was recorded for $60 \mathrm{~min}$ while the mice breathed under normoxic conditions. To observe hypoxia-induced ventilatory responses, the inspired gas was switched to $10 \% \mathrm{O}_{2}+90 \% \mathrm{~N}_{2}$ for $15 \mathrm{~min}$ and to $5 \% \mathrm{O}_{2}+95 \% \mathrm{~N}_{2}$ for $15 \mathrm{~min}$. To determine the ventilatory response to $\mathrm{CO}_{2}$, baseline ventilation was determined while mice breathed $21 \% \mathrm{O}_{2}+89 \% \mathrm{~N}_{2}$, and the inspired gas was switched to a hypercapnic gas $\left(21 \% \quad \mathrm{O}_{2}+5 \% \quad \mathrm{CO}_{2}+74 \% \quad \mathrm{~N}_{2}\right)$. All recordings were made at an ambient temperature of $22-24{ }^{\circ} \mathrm{C}$. Variables analyzed were $R R, V_{T}$, and $V_{E}$ (minute ventilation).

\section{Measurements of blood pressure and plasma catecholamines.} Blood pressures were determined using the tail-cuff method in conscious mice using a noninvasive BP system (Softron Instruments, Beijing, China); mean (MBP), systolic (SBP), and diastolic (DBP) blood pressure levels were measured. Plasma norepinephrine levels were determined by immunoassay. Blood from adult mice was collected into heparinized tubes placed on ice and was then centrifuged at $3000 \mathrm{~g}$ for $5 \mathrm{~min}$ at $4{ }^{\circ} \mathrm{C}$ to separate the plasma. Plasma catecholamine levels were quantified by immunoassay according to the manufacturer's instructions (IBL-Hamburg, Hamburg, Germany).

Western blot analysis. CBs were harvested from anesthetized $\mathrm{CHL} 1^{+1+}$ and $\mathrm{CHL} 1^{-1-}$ mice, and total protein was extracted. Equal amounts of protein $(50-100 \mu \mathrm{g})$ were boiled in sample buffer, separated by electrophoresis on $8-12 \%$ SDS-PAGE gels, and transferred to a nitrocellulose membrane for $1-3 \mathrm{~h}$. Membranes were blocked in $5 \%$ skimmed-milk powder in TBS-T (TBS plus $0.5 \%$ Tween-20) or in $3 \%$ BSA in TBS-T for $2 \mathrm{~h}$ at room temperature, and then incubated overnight at $4{ }^{\circ} \mathrm{C}$ with primary antibody. Primary antibodies included CHL1 (1:500; R\&D Systems), TH (1:2000; Millipore), Nestin (1:500; Millipore), GFAP (1:1000; DAKO), and $\beta$-actin (1:10000; Sigma, St. Louis, MO, USA). Membranes were treated with goat anti-mouse or -rabbit HRP-conjugated secondary antibodies (1:5000, MBL). Complexes on the membrane were visualized using an enhanced chemiluminescence (ECL) detection system (Pierce, Rockford, IL, USA).

Hypoxic treatment. I Mice were exposed to a low-oxygen chamber with gas mixture to hypoxic air (5\% oxygen, balance with nitrogen) for $10 \mathrm{~min}$. II Mice were exposed to acute hypobaric hypoxia of $10000 \mathrm{~m}$ at a velocity of $50 \mathrm{~m} / \mathrm{s}$ for $15 \mathrm{~min}$. Humidity in the chamber was maintained at $40-50 \%$ and temperature at $22-24^{\circ} \mathrm{C}$. Survival rate and survival time were measured in $\mathrm{CHL} 1^{+1+}$ and $\mathrm{CHL} 1^{-1}$ mice in these models within a certain time (10 and $15 \mathrm{~min})$. The maximal survival time is $10 \mathrm{~min}(600 \mathrm{~s})$ or $15 \mathrm{~min}(900 \mathrm{~s})$ if the mice still survive to hypoxic exposure. III Mice were exposed to a hypoxia chamber with gas mixture to hypoxic air ( $8 \%$ oxygen, balance with nitrogen) for $6 \mathrm{~h}$; thereafter, CBs were harvested, and total protein was extracted for SDS-PAGE.

Statistical analysis. All experiments were repeated at least three times, and the measurements were recorded by the observers who were blinded to the groups. Data are presented as group mean values with S.E.M. Asterisks identify experimental groups that were significantly different from control groups according to the Student $t$-test or one-way ANOVA. For all analyses, $P$-values $<0.05$ were considered significant.

\section{Conflict of Interest}

The authors declare no conflict of interest.
Acknowledgements. This work was supported by a grant from the Natural Sciences Foundation of China, No. 31000524 and the Beijing Natural Science Foundation, No. 5132025 and the National Basic Research Program of China (No. 2011CB910800 and No. 2012CB518200) and the Li Kashing Foundation. MS is New Jerseay Professor of Spinal Cord Research.

\section{Author Contributions}

Xin Huang: Provision of study material or patients, collection and/or assembly of data, data analysis and interpretation, and manuscript writing. Jia Sun: Provision of study material or patients, collection and/or assembly of data. Weifang Rong: Collection and/or assembly of data, data analysis and interpretation, and manuscript writing. Tong Zhao: Provision of study material or patients. Dahu Li: Collection and/ or assembly of data. Xuefeng Ding: Collection and/or assembly of data. Liying Wu: Collection and/or assembly of data. Kuiwu Wu: Collection and/or assembly of data. Melitta Schachner: Provision of study material or patients, data analysis, and interpretation. Zhi-Cheng Xiao: Data analysis and interpretation, data analysis, and interpretation. Lingling Zhu: Provision of study material or patients, data analysis and interpretation, manuscript writing, financial support, and final approval of manuscript. Ming Fan: Data analysis and interpretation, financial support, and final approval of manuscript.

1. Holm J, Hillenbrand R, Steuber V, Bartsch U, Moos M, Lubbert H et al. Structural features of a close homologue of $L 1$ (CHL1) in the mouse: a new member of the L1 family of neural recognition molecules. Eur J Neurosci 1996; 8: 1613-1629.

2. Rolf B, Lang D, Hillenbrand R, Richter M, Schachner M, Bartsch U. Altered expression of $\mathrm{CHL} 1$ by glial cells in response to optic nerve injury and intravitreal application of fibroblast growth factor-2. J Neurosci Res 2003; 71: 835-843.

3. Nishimune H, Bernreuther C, Carroll P, Chen S, Schachner M, Henderson CE. Neural adhesion molecules L1 and CHL1 are survival factors for motoneurons. J Neurosci Res 2005; 80: 593-599.

4. Angeloni D, Lindor NM, Pack S, Latif F, Wei MH, Lerman MI. CALL gene is haploinsufficient in a 3p- syndrome patient. Am J Med Genet 1999; 86: 482-485.

5. Senchenko VN, Krasnov GS, Dmitriev AA, Kudryavtseva AV, Anedchenko EA, Braga EA et al. Differential expression of $\mathrm{CHL1}$ gene during development of major human cancers. PloS One 2011; 6: e15612.

6. Kuhn PH, Koroniak K, Hogl S, Colombo A, Zeitschel U, Willem M et al. Secretome protein enrichment identifies physiological BACE1 protease substrates in neurons. EMBO J 2012; 31: 3157-3168.

7. Montag-Sallaz M, Schachner M, Montag D. Misguided axonal projections, neural cell adhesion molecule $180 \mathrm{mRNA}$ upregulation, and altered behavior in mice deficient for the close homolog of L1. Mol Cell Biol 2002; 22: 7967-7981.

8. Pratte M, Rougon G, Schachner M, Jamon M. Mice deficient for the close homologue of the neural adhesion cell $\mathrm{L} 1(\mathrm{CHL} 1)$ display alterations in emotional reactivity and motor coordination. Behav Brain Res 2003; 147: 31-39.

9. Jakovcevski I, Wu J, Karl N, Leshchyns'ka I, Sytnyk V, Chen J et al. Glial scar expression of CHL1, the close homolog of the adhesion molecule L1, limits recovery after spinal cord injury. J Neurosci 2007; 27: 7222-7233.

10. Huang $X$, Zhu LL, Zhao T, Wu LY, Wu KW, Schachner M et al. CHL1 negatively regulates the proliferation and neuronal differentiation of neural progenitor cells through activation of the ERK1/2 MAPK pathway. Mol Cell Neurosci 2011; 46: 296-307.

11. Sun J, Huang X, Zhu LL, Wu KW, Fan M. [Influence of acute hypoxia on CHL1 expression in different tissues of mice]. Zhongguo Ying Yong Sheng Li Xue Za Zhi 2011; 27: 280-283.

12. Lopez-Barneo J, Ortega-Saenz P, Pardal R, Pascual A, Piruat JI, Duran R et al. Oxygen sensing in the carotid body. Annals NY Acad Sciences 2009; 1177: 119-131.

13. Nanduri J, Makarenko V, Reddy VD, Yuan G, Pawar A, Wang N et al. Epigenetic regulation of hypoxic sensing disrupts cardiorespiratory homeostasis. Proc Natl Acad Sci USA 2012; 109: 2515-2520.

14. Ortega-Saenz P, Pascual A, Piruat JI, Lopez-Barneo J. Mechanisms of acute oxygen sensing by the carotid body: lessons from genetically modified animals. Resp Physiol Neurobiol 2007; 157: 140-147.

15. Kline DD, Peng YJ, Manalo DJ, Semenza GL, Prabhakar NR. Defective carotid body function and impaired ventilatory responses to chronic hypoxia in mice partially deficient for hypoxia-inducible factor 1 alpha. Proc Natl Acad Sci USA 2002; 99: 821-826.

16. Pardal R, Ortega-Saenz P, Duran R, Lopez-Barneo J. Glia-like stem cells sustain physiologic neurogenesis in the adult mammalian carotid body. Cell 2007; 131: 364-377.

17. Abdala AP, McBryde FD, Marina N, Hendy EB, Engelman ZJ, Fudim M et al. Hypertension is critically dependent on the carotid body input in the spontaneously hypertensive rat. J Physiol 2012; 590(Pt 17): 4269-4277.

18. Dahan A, Nieuwenhuijs D, Teppema L. Plasticity of central chemoreceptors: effect of bilateral carotid body resection on central CO2 sensitivity. PLoS Med 2007; 4: e239.

19. Campanucci VA, Fearon IM, Nurse CA. O2-sensing mechanisms in efferent neurons to the rat carotid body. Adv Exp Med Biol 2003; 536: 179-185. 
20. Teppema LJ, Dahan A. The ventilatory response to hypoxia in mammals: mechanisms, measurement, and analysis. Physiolog Rev 2010; 90: 675-754.

21. Peers $C$, Wyatt CN, Evans AM. Mechanisms for acute oxygen sensing in the carotid body. Respir Physiol Neurobiol 2010; 174: 292-298.

22. Lopez-Barneo J. Oxygen and glucose sensing by carotid body glomus cells. Curr Opin Neurobiol 2003; 13: 493-499.

23. Semenza GL. Oxygen sensing, homeostasis, and disease. N Engl J Med 2011; 365 : 537-547.

24. Koike MA, Lin AJ, Pham J, Nguyen E, Yeh JJ, Rahimian R et al. APP knockout mice experience acute mortality as the result of ischemia. PloS One 2012; 7: e42665.

25. Serra A, Brozoski D, Hedin N, Franciosi R, Forster HV. Mortality after carotid body denervation in rats. J Appl Physiol 2001; 91: 1298-1306.

26. Prabhakar NR. $\mathrm{O} 2$ sensing at the mammalian carotid body: why multiple $\mathrm{O}_{2}$ sensors and multiple transmitters? Exp Physiol 2006; 91: 17-23.

27. Prabhakar NR, Peng YJ. Peripheral chemoreceptors in health and disease. J Appl Physio 2004; 96: 359-366.

28. Gonzalez C, Almaraz L, Obeso A, Rigual R. Carotid body chemoreceptors: from natural stimuli to sensory discharges. Physiol Rev 1994; 74: 829-898.
29. Andreyeva A, Leshchyns'ka I, Knepper M, Betzel C, Redecke L, Sytnyk V et al. CHL1 is a selective organizer of the presynaptic machinery chaperoning the SNARE complex. PLOS One 2010; 5: e12018.

30. Leshchyns'ka I, Sytnyk V, Richter M, Andreyeva A, Puchkov D, Schachner M. The adhesion molecule $\mathrm{CHL} 1$ regulates uncoating of clathrin-coated synaptic vesicles. Neuron 2006; 52: 1011-1025.

31. Rong W, Gourine AV, Cockayne DA, Xiang Z, Ford AP, Spyer KM et al. Pivotal role of nucleotide P2 $\times 2$ receptor subunit of the ATP-gated ion channel mediating ventilatory responses to hypoxia. J Neurosci 2003; 23: 11315-11321.

(c) (1) $(\Theta$ Cell Death and Disease is an open-access journal published by Nature Publishing Group. This work is licensed under a Creative Commons Attribution-NonCommercialNoDerivs 3.0 Unported License. To view a copy of this license, visit http://creativecommons.org/licenses/by-nc-nd/3.0/

Supplementary Information accompanies this paper on Cell Death and Disease website (http://www.nature.com/cddis) 